\title{
Optimal policies under different assumptions about target values: An optimum control analysis for Austria
}

\author{
R. Neck and S. Karbuz \\ Department of Economics, University of Bielefeld \\ P.O.Box 1001 31, D - 33501 Bielefeld, Germany. \\ Tel: +495211064859. Fax: +495211062994. \\ e-mail: neckenw42. wiwi.uni-bielefeld.de
}

\begin{abstract}
Optimal fiscal and monetary policies for the period 1993 to 2000 are calculated for Austria within the framework of a problem of quantitative economic policy. An intertemporal objective function is minimized subject to the constraints of a macroeconometric model. Exogenous variables of the model are forecast by time series methods. Using the optimum control algorithm OPTCON, approximately optimal policies are determined. The sensitivity of optimal policies with respect to the target values of the objective variables is investigated. It is shown that when designing intertemporal optimization problems, one must avoid to be either too ambitious or too cautious with respect to the postulated targets.
\end{abstract}

\section{Keywords}

Optimal control, economics, sensitivity, optimization, forecasting

\section{INTRODUCTION}

When planning policies to influence the development of an economy, it is usually not sufficient to rely on simple rules. Instead, trade-offs and side-effects of policies on variables other than those at which they are aimed have to be taken into account. Quantitative informations on these effects as well as on intertemporal preferences of policy-makers are required. Ideally, there should be decision support systems available to assist policy-makers in planning appropriate economic policies.

In this paper, we analyze these issues within a problem of quantitative economic policy, using an optimum control approach. We determine numerically optimal monetary and fiscal policies

Financial support from the "Jubiläumsfonds der Oesterreichischen Nationalbank" (project no. 5126) is gratefully acknowledged. Karbuz acknowledges support from the Institute for Advanced Studiens, Vienna. 
for the nineties by minimizing an intertemporal objective function subject to the constraints given by an econometric model. The model, called FINPOL2, is a medium-size macroeconometric model for Austria. It relates policy and exogenous variables to objective variables of Austrian economic policies. Moreover, we postulate an objective function for Austrian policy-makers over the years 1993 to 2000, which penalizes deviations of objective variables from their desired values. The exogenous variables of the model are forecast over this planning horizon using time series methods. Next, we calculate optimal stabilization policies over this time horizon.

Here we are particularly interested in the sensitivity of optimal policies with respect to the target or "ideal" values of the objective variables from which deviations are penalized by the objective function. To answer this question, we perform several optimum control experiments under varying assumptions about the target paths of objective variables. The results show that there may be systematic dependences of optimal policies on these target paths. In particular, trade-offs between different policy goals may be sensitive with respect to postulated target values of the objective variables. This shows that when designing intertemporal optimization problems, and in particular when specifying an objective function numerically, one must avoid to be either too ambitious or too cautious with respect to the postulated targets.

\section{THE ECONOMETRIC MODEL FINPOL2}

The model FINPOL2 is based on traditional Keynesian macroeconomic theory in the sense of conventional IS-LM/aggregate demand-aggregate supply models. Stochastic behavioral equations for the demand side include a consumption function, an investment function, an import function and an interest-rate equation as a reduced-form money market model. Prices are largely determined by aggregate demand variables. Disequilibrium in the labor market, as measured by the excess of unemployed persons over vacancies, is modelled to depend on the real GDP growth rate and the rate of inflation, embodying both an Okun's law-type relation and a rudimentary Phillips curve. The main objective variables of Austrian economic policies, such as real GDP, the labor market disequilibrium variable (related to the rate of unemployment), the rate of inflation, the balance of payments and the ratio of the federal net budget deficit to GDP, are related directly or indirectly to those fiscal and monetary policy instruments which are used as control variables, namely to federal budget expenditures and revenues and to money supply.

The model, which is dynamic and nonlinear, was estimated first by OLS and then by simultaneous equations estimation methods using annual data over the period 1965 to 1992. Data have been obtained from the Austrian Institute of Economic Research (WIFO). All real data have dimension billions of 1983 Austrian Shillings. The estimates and test statistics together with ex-post simulation results suggest that the model provides a reasonable account of the development of economic variables in the recent past. Here we use the estimates of the parameters obtained by three-stage least squares. These estimation results together with the statistical characteristics of the regressions are given in Neck and Karbuz (1994). 
In the theory of quantitative economic policy, optimum control theory has been used in several studies to determine optimal policies for econometric models (e.g., Chow 1975, 1981, Kendrick 1981). Here we use the algorithm OPTCON, developed by Matulka and Neck (1992); it determines approximate solutions of deterministic or stochastic optimum control problems with a quadratic objective function and a nonlinear multivariable dynamic model. The objective function is quadratic in the deviations of the state and control variables from their respective desired values. The dynamic system is required to be given in a state space representation.

For our simulation experiments, we choose the planning horizon as 1993 to 2000 . Among the variables whose deviations from desired values are to be penalized, we distinguish two categories: First, there are five "main" objective variables which are of direct political relevance in assessing the performance of the Austrian economy. These are the rate of inflation (PV\% $\left.{ }_{t}\right)$, the labor market excess supply variable $\left(\mathrm{UN}_{\mathrm{t}}\right)$ as a measure for involuntary unemployment, the rate of growth of real GDP $(\mathrm{YR} \% \mathrm{t})$, the balance of current account $\left(\mathrm{LBR}_{\mathrm{t}}\right)$, and the federal net budget deficit as percentage of GDP $(\mathrm{DEF} \% \mathrm{q}$ ). In all experiments, the desired levels for labor market excess supply $\left(\mathrm{UN}_{\mathrm{t}}\right)$ and the balance of current account $\left(\mathrm{LBR}_{\mathrm{t}}\right)$ are set equal to zero. Thus, we want to achieve equilibrium in the labor market and in the external relations. Assumptions about the desired (target) values for the rate of inflation ( $\mathrm{PV} \% \mathrm{t}$ ), the real growth rate (YR\% $\%_{t}$ ), and the deficit variable $\mathrm{DEF} \% \mathrm{t}$ vary among different experiments.

Second, we introduce a category of "minor" objective variables. These include real private consumption $\left(C_{t}\right)$, real private investment $\left(\mathrm{IR}_{t}\right)$, real imports of goods and services $\left(\mathrm{MR}_{\mathrm{t}}\right)$, the nominal rate of interest $\left(R_{t}\right)$, real GDP $\left(Y_{t}\right)$, real total aggregate demand $\left(V_{t}\right)$, the domestic price level $\left(\mathrm{PY}_{\mathrm{t}}\right)$, the price level of public consumption $\left(\mathrm{PG}_{t}\right)$, nominal public consumption $\left(G_{t}\right)$, and nominal public-sector net tax revenues $\left(T_{t}\right)$, as well as the policy instrument (control) variables money supply $\left(\mathrm{Ml}_{\mathrm{t}}\right)$, federal budget net expenditures $\left(\mathrm{NEX}_{\mathrm{t}}\right)$ and federal budget tax receipts $\left(B I N_{t}\right)$. We take 1992 historical values of these "minor" objective variables (except for $R_{t}$ ) to be given and postulate desired growth rates for the planning horizon, which are varied in accordance with the target values for $\mathrm{YR} \%_{t}$ and $\mathrm{PV} \% \mathrm{t}$. The rate of interest $R_{t}$ has a desired constant value of 7 for all periods.

In the weight matrix of the objective function, all off-diagonal elements are set equal to zero, and the main diagonal elements are given weights of 10 for the "main" objective variables and of 1 for the "minor" objective variables. The state variables that are not mentioned above get weights of zero, thus being regarded as irrelevant to the hypothetical policy-maker. The weight matrix is assumed to be constant over time.

For a simulation over a future planning horizon, projections (forecasts) of the exogenous (controlled and non-controlled) variables are needed. Here we use extrapolations of these variables for the years 1993 to 2000 calculated from linear stochastic time series models of the ARMA (mixed autoregressive-moving average process) type. After several trials and applying the usual diagnostic checking procedure for the time series under consideration, we decided to model money supply $\left(\mathrm{Ml}_{\mathrm{t}}\right)$ by an ARMA $(2,1)$ process, federal budget expenditures $(\mathrm{NEX})$ by an ARMA $(2,1)$ process, federal budget revenues $\left(\mathrm{BIN}_{t}\right)$ by an ARMA $(2,2)$ process, the import price level $\left(\mathrm{PM}_{t}\right)$ by an ARMA $(1,1)$ process, real exports of goods and services $\left(\mathrm{XR}_{t}\right)$ by an ARMA $(2,3)$ process, and the inventory change variable $I_{\mathrm{I}}$ by an AR (1) process.

The forecasts from these time series models imply moderate growth of the fiscal policy variables. The extrapolation implies that the federal budget deficit $\left(\mathrm{NDEF}_{t}\right)$ gets stabilized and 
falls gradually from 70.3 billions AS in 1993 to 60.5 billions AS in 2000 , which seems to be a rather optimistic forecast. The development of the foreign sector variables $\mathrm{PM}_{t}$ and $\mathrm{XR}_{t}$ is even more optimistic: $\mathrm{PM}_{t}$ grows only by $1 \%$ p.a. or less, and $\mathrm{XR}_{t}$ grows by 5 to $7 \%$ p.a. $\mathrm{IIR}_{\mathrm{t}}$ is positive but falling. Money supply $\mathrm{M} 1_{\mathrm{t}}$ grows by 5 to $5.8 \%$ p.a.

As a first step, the model was simulated over the years 1993 to 2000 using the extrapolations of all exogenous variables from the time series models as input. This amounts to a dynamic forecast of the endogenous variables of the model. Next, we performed several optimization experiments. Here again the projections of the non-controlled exogenous variables from the time series models are used as inputs, being assumed to be known for certain, but the values of the policy instruments are determined endogenously as (approximately) optimal under the assumed objective function. In this paper, we are considering on'y the results of deterministic optimization experiments, a't'ough the a'gorithm OPTCON can solve stochastic control problems with additive and parameter errors as well. In several experiments, we found the results of deterministic and fully stochastic optimization runs to be very similar. Therefore we decided to concentrate on deterministic runs for a sensitivity analysis.

The projection scenario forecasts a recession for 1993 (or actually a continuation of the recession from 1992): growth of real GDP (YR\% $\%_{t}$ ) is negative, the rate of unemployment (related to $\mathrm{UN}_{\mathrm{t}}$ ) is high, the balance of trade $\left(\mathrm{LBR}_{t}\right)$ exhibits a deficit, the rate of inflation $\left(\mathrm{PV} \%_{\mathrm{t}}\right)$ is moderate, and the ratio of the federal budget deficit to GDP (DEF\% $\%_{t}$ ) is high. Starting in 1994, however, a period of relatively high growth is projected, which is clearly above the one obtained on average during the eighties. The labor market excess supply variable $\left(\mathrm{UN}_{t}\right)$ falls gradually, with only slightly rising inflation $(\mathrm{PV} \% \mathrm{t})$. High surpluses are obtained for the balance of trade $\left(\mathrm{LBR}_{t}\right)$, and the deficit variable $\mathrm{DEF} \% \mathrm{t}$ falls gradually.

\section{OPTIMAL POLICIES UNDER DIFFERENT ASSUMPTIONS ABOUT TARGET VALUES}

In order to assess the scope for optimal stabilization policies, we conducted several optimization experiments with the model and the assumed intertemporal objective function. We are particularly interested in the sensitivity of optimal policies with respect to the target paths of the budget deficit on the one hand and of real and price variables on the other hand. As a benchmark, for experiment 1 we assume that the aim of the policy-maker consists in consolidating the federal budget deficit gradually such that the desired value of $\mathrm{DEF} \% \mathrm{t}$ is reduced by 0.3 percentage points each year, from the historical value of $3.27 \%$ in 1992 down to $0.87 \%$ in 2000 . Moreover, we consider $2 \%$ p.a. as the desired rate of inflation ( $(\mathrm{PV} \% \mathrm{t}$ ) and $3.5 \%$ p.a. as the desired real growth rate $(\mathrm{YR} \% \mathrm{t})$. In order to make target values consistent for the model variables, we also assume desired growth rates of $3.5 \%$ p.a. for all real variables, desired growth rates of $2 \%$ p.a. for the price level variables, and desired growth rates of $5.5 \%$ p.a. for the nominal variables among the "minor" objective variables.

Results for the instrument variables and the "main" objective variables from experiment 1 are given in Table 1. Optimal monetary and especially fiscal policies are more countercyclical than projected ones and imply smoother time paths of the endogenous variables of the model. The recession of 1993 is avoided by expansionary budgetary policies. Federal budget expenditures $\left(\mathrm{NEX}_{\mathrm{t}}\right)$ are higher and federal budget revenues $\left(\mathrm{BIN}_{\mathrm{t}}\right)$ are lower than both projected and desired levels of the variables. This results in a positive growth rate, lower unemployment, only 
slightly higher inflation, but distinctly higher deficits of the trade balance and the federal budget as compared to the projection. Also in 1994, optimal stabilization policies can be characterized as expansionary. The values of the instrument variables in 1995 and 1996 are close to those of the projection. From 1997 on, optimal monetary and fiscal policies are restrictive as compared to the projection. This results in lower growth, higher unemployment and lower inflation than in the reference scenario. The surplus of the trade balance starts increasing some years later than in the projection. The federal budget gets fully consolidated, with a balanced budget in 1999 and even a surplus in 2000 . The optimal levels of aggregate demand and its components (private consumption, investment, government consumption, imports, tax revenues) all grow faster during the recession than in the projection. For the entire time horizon, however, optimal growth is slightly weaker on average than in the reference scenario.

Table 1 Optimal values of instruments and "main" objectives, experiment 1

\begin{tabular}{ccccccccc}
\hline year & $M I_{t}$ & $N E X_{t}$ & $B I N_{t}$ & $P V \%_{t}$ & $U N_{t}$ & $Y R \%_{t}$ & $L B R_{t}$ & DEF\%t \\
\hline 1993 & 326.892 & 734.641 & 581.421 & 2.063 & 4.807 & 1.996 & -22.144 & 7.196 \\
1994 & 340.949 & 769.752 & 639.456 & 2.597 & 4.112 & 4.632 & -7.253 & 5.671 \\
1995 & 355.651 & 789.774 & 698.940 & 2.753 & 3.454 & 4.943 & 9.858 & 3.644 \\
1996 & 373.033 & 833.577 & 746.124 & 2.658 & 3.428 & 3.365 & 12.669 & 3.282 \\
1997 & 390.509 & 870.066 & 806.048 & 2.712 & 3.278 & 3.769 & 22.733 & 2.238 \\
1998 & 409.455 & 907.822 & 870.236 & 2.681 & 3.279 & 3.390 & 32.310 & 1.229 \\
1999 & 430.907 & 937.960 & 934.985 & 2.692 & 3.245 & 3.502 & 44.772 & 0.091 \\
2000 & 457.717 & 959.630 & 974.370 & 2.838 & 2.920 & 4.423 & 55.274 & -0.416 \\
\hline
\end{tabular}

In order to investigate whether the consolidation of the federal budget is due to the ambitious goal of deficit reduction, we conducted an experiment where the target value of the deficit variable $\mathrm{DEF} \% \mathrm{t}$ was set at a constant value of $2.5 \%$ of GDP for the entire planning horizon. The results are nearly identical to those of experiment 1 . Monetary policy $\left(M 1_{t}\right)$ is slightly more restrictive after 1994 , and fiscal policies $\left(\mathrm{NEX}_{\mathrm{t}}\right.$ and $\left.\mathrm{BIN}_{\mathrm{t}}\right)$ are slightly more expansionary than in experiment 1 . The effects on the endogenous variables, including the federal budget deficit, are negligible as compared to experiment 1 . The same holds true if we assume a constant desired value of $3.27 \%$ (the historical value of 1992) for DEF\%, and if we apply these modifications of the target values of the budget deficit to the experiments to be described below. From this, we conclude that in our model there is nearly no influence of the target values of the deficit variable $\mathrm{DEF} \% \mathrm{t}$ on optimal policies, at least for "realistic" (not extreme) desired values of this variable.

The situation is quite different if we modify the target values of the real growth rate and of the inflation rate. In the following experiments, we retain the target values for $\mathrm{DEF} \%$ from experiment 1. First, in experiment 2, we assume a desired growth rate of $2.5 \%$ for all real variables (and the same value for YR\% $\%_{t}$ ); the "ideal" value of the inflation rate (and of the growth rates of all price level variables in the model) is kept at $2 \%$, and nominal variables get desired growth rates of $4.5 \%$. This scenario, which can be interpreted as "pessimistic" with respect to the growth potential of the Austrian economy, gives results as shown in Table 2. Now optimal monetary and fiscal policies are considerably more restrictive than in experiment 
1. In particular, money supply $\left(\mathrm{M}_{t}\right)$ and federal budget expenditures $\left(\mathrm{NEX}_{\mathrm{t}}\right)$ are always lower, and federal budget revenues $\left(B N_{t}\right)$, except for 1993 and 2000 , are higher than in experiment 1 . Especially in the later years of the planning horizon, all instruments follow a much more contractionary course than prescribed by their desired values. This implies a lower budget deficit than in experiment 1 , with increasing budgetary surpluses starting already in 1997. Inflation (PV\%) and real GDP growth (YR\% $\%_{t}$ ) are lower, balance-of-payments surplus $\left(\mathrm{LBR}_{t}\right)$ and involuntary unemployment $\left(\mathrm{UN}_{\mathrm{t}}\right)$ are higher than in experiment 1 , especially during the last years of the planning horizon. Real, price, and nominal variables show lower levels than before, though they are still higher than their desired values.

Table 2 Optimal values of instruments and "main" objectives, experiment 2

\begin{tabular}{|c|c|c|c|c|c|c|c|c|}
\hline year & $M I_{t}$ & $N E X_{t}$ & $B I N_{t}$ & PV\%t & $U N_{t}$ & $Y R \%_{t}$ & $L B R_{t}$ & $D E F \%_{t}$ \\
\hline 1993 & 320.153 & 729.821 & 580.292 & 2.037 & 4.872 & 1.793 & -21.549 & 7.039 \\
\hline 1994 & 329.337 & 752.361 & 639.641 & 2.499 & 4.373 & 3.982 & -4.279 & 4.953 \\
\hline 1995 & 338.872 & 760.214 & 699.379 & 2.613 & 3.862 & 4.328 & 16.540 & 2.482 \\
\hline 1996 & 350.561 & 790.330 & 747.983 & 2.479 & 3.958 & 2.744 & 24.135 & 1.630 \\
\hline 1997 & 361.905 & 810.652 & 811.039 & 2.489 & 3.932 & 3.077 & 40.133 & -0.014 \\
\hline 1998 & 374.699 & 828.230 & 879.139 & 2.404 & 4.078 & 2.565 & 57.037 & -1.744 \\
\hline 1999 & 391.084 & 831.175 & 942.304 & 2.376 & 4.159 & 2.688 & 77.951 & -3.597 \\
\hline 2000 & 415.876 & 817.178 & 956.712 & 2.602 & 3.673 & 4.404 & 95.190 & -4.192 \\
\hline
\end{tabular}

These effects are intensified if we retain the specification of experiment 2 , but assume more "optimistic" desired values for the price level variables and for the inflation rate by targeting zero inflation (implying "ideal" growth rates of $2.5 \%$ for nominal variables). Now all instrument variables exhibit lower values than in experiment 2 . Money supply $\left(\mathrm{M1}_{\mathrm{t}}\right.$ ) grows very slowly, federal budget expenditures $\left(\mathrm{NEX}_{t}\right)$ even decline over the entire period, and federal budget revenues $\left(\mathrm{BIN}_{\mathrm{t}}\right)$ grow less than in experiment 2 , resulting in a distinctly lower budget deficit (with a high surplus at the end of the planning horizon). All instrument variables show more contractionary behavior than their desired values. The rate of interest is higher, the rate of inflation (PV\%t) only slightly lower than before; effects on growth $(\mathrm{YR} \% \mathrm{t})$ and labor market excess supply $\left(\mathrm{UN}_{\mathrm{t}}\right)$ differ between different years. Over the entire planning period, endogenous real variables mostly grow slightly more than in experiment 2 , but less than in experiment 1 . The behavior of nominal and price variables is similar as in experiment 2 , in spite of the more ambitious goal regarding inflation. Nearly all endogenous variables are above their desired values, even with these very restrictive monetary and fiscal policies. From the point of view of actual policy-making, one can conclude that here (as already in experiment 2) the growth targets are too "pessimistic"; in addition, price targets are clearly too "optimistic", as prices do not react strongly upon these restrictive stabilization policies.

To explore the influence of growth and price targets further, we next assume more "optimistic" desired values for real economic variables. In experiment 3 , we set the "ideal" growth rate of real variables at $4.5 \%$, of price variables at $2 \%$ as in experiment 1 , and of nominal variables at $6.5 \%$. Results are given in Table 3. As compared to experiment 1 , the behavior of the instruments from experiment 2 is now reversed: money supply $\left(\mathrm{Ml}_{\mathfrak{t}}\right)$ and 
federal budget expenditures $\left(\mathrm{NEX} \mathrm{X}_{\mathrm{t}}\right)$ are always higher, federal budget revenues $\left(\mathrm{BIN}_{\mathrm{t}}\right)$, except for 1993 and 2000, are lower than in experiment 1, implying a more expansionary policy stance, also if compared with the desired values or the instrument variables. In this experiment, the federal budget does not get consolidated, with budget deficits being always higher than in experiment 1 and well above 100 billions Austrian Shillings until 2000. Prices and inflation rates, levels and growth rates of real variables, and levels of nominal variables are higher than in experiment 1 ; involuntary unemployment and especially the surplus of the trade balance are lower. The real GDP growth rate (YR\%t) is close to its desired values. Among the "minor" objective variables, private consumption (after 1995), imports and prices are above, investment and real GDP are below their target values. Given the relatively "optimistic" forecast of the non-controlled exogenous variables, this scenario might seem to be attractive to policy-makers, although the budgetary goals are not fulfilled.

Table 3 Optimal values of instruments and "main" objectives, experiment 3

\begin{tabular}{ccccccccc}
\hline year & $M 1_{t}$ & $N E X_{t}$ & $B I N_{t}$ & $P V \% t$ & $U N_{t}$ & $Y \%_{t}$ & $L B R_{t}$ & DEF\%t \\
\hline 1993 & 333.789 & 739.023 & 582.922 & 2.084 & 4.754 & 2.162 & -22.628 & 7.318 \\
1994 & 352.870 & 786.984 & 639.412 & 2.695 & 3.860 & 5.287 & -10.056 & 6.364 \\
1995 & 372.988 & 819.558 & 698.488 & 2.895 & 3.047 & 5.572 & 3.316 & 4.776 \\
1996 & 396.450 & 877.711 & 743.917 & 2.842 & 2.890 & 4.010 & 1.191 & 4.896 \\
1997 & 420.590 & 931.508 & 800.041 & 2.946 & 2.605 & 4.497 & 5.003 & 4.438 \\
1998 & 446.321 & 991.361 & 859.446 & 2.975 & 2.452 & 4.256 & 6.734 & 4.115 \\
1999 & 473.424 & 1051.620 & 925.636 & 3.026 & 2.302 & 4.331 & 10.116 & 3.626 \\
2000 & 502.602 & 1112.188 & 992.553 & 3.081 & 2.152 & 4.416 & 13.510 & 3.173 \\
\hline
\end{tabular}

Finally, in experiment 4 we explore the consequences of "optimistic" target values for both real growth and price variables. Growth of real variables is targeted at $4.5 \%$, growth of price variables at zero, and growth of nominal variables at $4.5 \%$. The results are shown in Table 4 .

Table 4 Optimal values of instruments and "main" objectives, experiment 4

\begin{tabular}{rcccccccc}
\hline year & $M I_{t}$ & $N E X_{t}$ & $B I N_{t}$ & $P V \%_{t}$ & $U N_{t}$ & $Y R_{t}$ & $L B R_{t}$ & DEF\%t \\
\hline 1993 & 325.227 & 727.011 & 569.407 & 2.089 & 4.743 & 2.198 & -22.734 & 7.386 \\
1994 & $\mathbf{3 3 6 . 2 7 7}$ & 756.827 & 616.236 & 2.694 & 3.857 & 5.266 & -10.180 & 6.062 \\
1995 & $\mathbf{3 4 7 . 5 1 3}$ & 768.905 & 664.994 & 2.893 & 3.051 & 5.552 & 3.239 & 4.099 \\
1996 & 361.245 & $\mathbf{8 0 4 . 1 2 9}$ & 699.356 & 2.836 & 2.905 & 3.973 & 1.268 & 3.836 \\
1997 & $\mathbf{3 7 4 . 9 1 5}$ & $\mathbf{8 3 2 . 0 1 5}$ & $\mathbf{7 4 3 . 4 9 7}$ & 2.934 & 2.939 & 4.431 & 5.418 & 2.992 \\
1998 & $\mathbf{3 8 9 . 7 8 7}$ & $\mathbf{8 6 2 . 0 2 7}$ & $\mathbf{7 8 8 . 5 2 0}$ & 2.957 & 2.500 & 4.190 & 7.640 & 2.297 \\
1999 & 406.448 & $\mathbf{8 8 7 . 6 7 2}$ & $\mathbf{8 3 3 . 0 5 0}$ & $\mathbf{3 . 0 3 2}$ & 2.307 & 4.438 & 10.998 & 1.574 \\
2000 & 426.678 & 912.031 & $\mathbf{8 6 3 . 4 7 4}$ & 3.192 & 1.929 & 5.118 & 11.684 & 1.279 \\
\hline
\end{tabular}


All instruments have values well below those of experiments 1 and 3 , and the course of stabilization policies is more expansionary than in experiment 2 . As compared to their desired values, the instruments act in a countercyclical manner, being set at more expansionary values in the first years and at more restrictive values in the last years of the planning period. Comparing the results for the endogenous variables to those from experiment 3 , it can be seen that except for public-sector variables, real economic variables grow more over the entire planning period, which is due to the more expansionary (lower) values of budget revenues $\left(\mathrm{BIN}_{t}\right)$, which are a rather effective instrument in our model. With respect to prices, this expansionary effect of the revenue side of the budget is compensated by more restrictive money supply $\left(\mathrm{Ml}_{t}\right)$ and budget expenditures $\left(\mathrm{NEX}_{t}\right)$, and price variables (including inflation) have values very close to those of the previous experiment. Real GDP growth (YR\%t) is first lower, then higher than in experiment 3 , the balance of current account $\left(\mathrm{LBR}_{t}\right)$ is lower, and labor market excess supply $\left(\mathrm{UN}_{t}\right)$ is similar to that in experiment 3 . The deficit of federal budget is reduced over the planning horizon, but it remains above target values until 2000. By and large, these results could also be acceptable to a more "conservative" policy-maker, especially because they imply a smaller public sector than those of experiment 3 .

\section{CONCLUSIONS}

In this paper, we have examined the sensitivity of optimal stabilization policies for Austria during the nineties with respect to assumptions about target values of some objective variables in a framework of quantitative economic policy. The results show that it can be vital to avoid too "pessimistic" or too "optimistic" target values for some variables such as real quantities or prices; for the budget deficit, on the other hand, target values do not matter in our model. It also turns out that there is a trade-off between real growth and full employment on the one hand and price stability and budget consolidation on the other. Much more experiments are required to check whether these results hold true also for other econometric models. However, the present analysis can be seen as a first step towards developing a decision support system for policy-makers who, when confronted with results of alternative optimization experiments, should be assisted in revealing their preferences about macroeconomic policy objectives.

\section{REFERENCES}

Chow, G.C. (1975) Analysis and Control of Dynamic Economic Systems. Wiley, New York.

Chow, G.C. (1981) Econometric Analysis by Control Methods. Wiley, New York.

Kendrick, D. (1981) Stochastic Control for Economic Models. McGraw-Hill, New York.

Matulka, J. and Neck, R. (1992) OPTCON: An Algorithm for the Optimal Control of Nonlinear Stochastic Models. Annals of Operations Research 37: 375 - 401.

Neck, R. and Karbuz, S. (1994) Optimal Stabilization Policies for the Nineties: A Simulation Study for Austria, in Proceedings of the European Simulation Symposium 1994 (ed. A.R. Kaylan et al.), Vol. I, Istanbul. 